\title{
Optimal Allocation of UPQC for Power Quality Enhancement via GWO-SA Algorithm
}

\author{
Adel RIACHE \\ College of Europe \\ Belgium
}

Khadija Al Balushi

\author{
International Maritime College, Oman \\ khadijalbalushi8@gmail.com
}

\begin{abstract}
Unified Power Quality Conditioner (UPQC)" is deployed in power systems for overcoming the issues related with voltage dips or rises in source voltage. Moreover, it controls the load voltage and mitigates the entire problems related with voltage and current harmonics, thereby enhancing the power quality (PQ). Here, this work presents a $\mathrm{PQ}$ enhancement approach by integrating the optimization concept. For optimization purpose, this work deploys the "Grey Wolf Optimization with Self-adaptiveness (GWO-SA)" model. Here, the presented model determines the optimal allocation of UPQC by taking into consideration of power system loss, UPQC cost and stability as well. Further, the superiority of GWOSA is validated and compared over existing works with respect to varied measures such as cost and location analysis. From the analysis, the performance of the implemented work when the number of location $=1$ is $0.21 \%, 0.59 \%, 0.77 \%$ and $0.26 \%$ better than SLnO, GWO, DA and PSO, respectively at $0 \%$ loading condition.
\end{abstract}

Keywords: UPQC; D-FACTS device; DSTATCOM; Voltage stability; GWO-SA model.

\begin{tabular}{ll} 
Nomenclature & \\
\hline Abbreviations & Descriptions \\
\hline APF & Active Power Filters \\
BFSLF & Backward/Forward Sweep Load Flow \\
CS & Cuckoo Search \\
DSTATCOM & Distribution Static Compensator \\
DA & Dragonfly Optimization \\
EE & Energy Efficiency \\
FF & Firefly \\
GWO-SA & Grey Wolf Optimization With Self-Adaptiveness \\
MOPSO & Multi-Objective Particle Swarm Optimisation \\
PV & Photovoltaic \\
PF & Power Factor \\
PQ & Power Quality \\
PCC & Point Of Common Coupling \\
PSO & Particle Swarm Optimization \\
RDN & Radial Distribution Networks \\
SEU & Series Unit \\
SLnO & Sea Lion Optimization \\
SSVR & Static Series Voltage Regulator \\
THD & Total Harmonic Distortion \\
UPQC & Unified Power Quality Conditioner \\
UPQC-O & Open UPQC \\
VSI & Voltage Stability Index \\
\hline
\end{tabular}

\section{Introduction}

The most important objective of power system operations is efficiency. Power losses and voltage limits acts a key role in proficient functioning of electrical system. Therefore, sustaining the voltage within the allowable limits is significant for the better performance of the system [6]. There are diverse devices to 
manage the issues on voltage enhancement namely, series capacitors, voltage regulators and so on. However, the disadvantages with these devices are resonance and slower response [7].

SSVR is a D-FACTS device utilized for enhancing the voltages in distribution network. The shunt DFACT device termed as DSTATCOM offers reactive power compensation for reducing power loss. Diverse optimization techniques like PSO, FF and so on were exploited for optimal allocation of D-STATCOM [8]. The functionalities of shunt and series D-FACTS are offered by UPQC. UPQC is a versatile D-FACTS device used for enhancing the voltage and for minimizing the power loss in network [9].

The UPQC comprises of 2 voltage source inverters, which were linked to a DC energy storing capacitor, which could be deployed to improve flickers, unbalances, and harmonics, as well as voltage sags, dynamic reactive and active power regulations [10] [11]. The series component introduces voltage for balancing the network with zero distortion. Likewise, UPQC shunt component feeds balances the current at PCC bus in a sinusoidal manner [12] [13]. To carry out this operation, shunt capacitors are deployed. Moreover, optimal allocation and rating of these capacitors is necessary as it assists in reducing the power losses in the network

The arrangement of the work is specified as: Section II portrays the review. Section III explains the UPQC model and section IV portrays the optimal allocation and sizing of UPQC via GWO-SA algorithm. Section V illustrates the outcomes and the paper is summarized in section VI.

\section{Literature Review}

\subsection{Related works}

In 2018, Ganguly and Lakshmi [1] have presented a novel allocation approach for UPQC-O incorporated $\mathrm{PV}$ generation system in RDN for improving the PQ and EE. In addition, the operational parameters like bus voltage were determined via "forward-backward sweep load flow". Moreover, PSO was exploited that determined the optimal allocation of UPQC in RDN networks.

In 2020, Jian et al. [2] have presented an optimal approach for UPQC that depends on hierarchical metaheuristic concept. In addition, the adopted model takes account of 3 objectives that included (a) minimization of load voltage variation and (b) maximization of PF; (c) minimization of the total UPQC power. These objectives were partitioned in to varied multi objectives for attaining better solution. Eventually, analysis was carried out that proved the supremacy of the adopted scheme.

In 2019, Lakshmi and Sanjib [3] have presented a multi-objective framework for optimally allocating open UPQC for saving the peak load of RDNs. The adopted model aided in mitigating various PQ issues. Here, maximal attainment of peak load saving, minimizing placement cost of UPQC-O, and minimizing total power loss were considered as the objectives. Moreover, MOPSO was deployed for optimizing these objectives that offered better solutions.

In 2016, Kumara and Srikanth [4] have developed FF and CS models for optimal allocation of UPFC, which in turn improved the stability of the system. Here, the FF approach has optimized the maximal power loss via appropriate position of UPFC. Moreover, the dynamic stability parameters were restored into secured limits by means of optimal UPFC capacity that in turn resulted in minimized cost.

In 2020, Ali and Amini [5] have presented a precise modelling of UPQC-O along with its incorporation in BFSLF. Moreover, the performance of SEU that was accountable for voltage sag compensation was limited in this work. In addition, an operational technique was introduced for improving the SEU performance. Finally, evaluation was carried out the portrayed the development of the presented model in overcoming minimal voltage sags.

\section{UPQC Model}

The model of UPQC is revealed in Fig 1. The UPQC involves series APF as well as shunt APF. Here, the latter one is connected across the loads that resolve the issues namely, "power factor enhancement, reactive power compensation, compensation of load unbalance, current harmonic and dc link voltage control". Accordingly, the series APF performs as controlled voltage source that resolves issues such as flicker, voltage harmonics and so on. The UPQC lessens the load interruption zone into a normal operating zone. Also, it reduces the voltage sags and unbalances, which in turn minimizes the power loss. The operation of shunt inverter and series inverter is depicted as follows: the series inverter voltage, $\mathrm{V}_{\mathrm{se}}$ depends on maximal voltage sag that must be reduced. The source voltage magnitudes during voltage sags and usual states are signified as $\mathrm{V}_{\mathrm{s}}=\mathrm{V}_{\mathrm{SO}}$ and $\mathrm{V}_{\mathrm{s}}=\mathrm{mV}_{\mathrm{SO}}$. Here, $\mathrm{m}_{\mathrm{sag}}=(1-\mathrm{m})$. At all conditions, load 
voltage, $\mathrm{V}_{\mathrm{L}}=\mathrm{V}_{\mathrm{SO}}=\mathrm{V}_{\mathrm{s}}$. The requisite series voltage inoculation for minimizing $\mathrm{m}_{\text {sag }} \mathrm{p}$.u of sags is computed as shown in Eq. (1).

$$
\begin{aligned}
\mathrm{V}_{\mathrm{se}} & =\sqrt{\mathrm{V}_{\mathrm{L}}^{2}+\left(\mathrm{mV}_{\mathrm{SO}}\right)^{2}-2 \mathrm{~V}_{\mathrm{L}}\left(\mathrm{mV}_{\mathrm{SO}}\right) \cos \delta} \\
& =\mathrm{V}_{\mathrm{s}} \sqrt{1+\mathrm{m}^{2}-2 \mathrm{~m} \cos \delta}
\end{aligned}
$$

Accordingly, $m V_{s} I_{s}=V_{L} I_{L} \cos \phi$ delivers source current as per Eq. (2), here $I_{L}$ and $I_{s}$ refers to loading current and compensated source-end current in that order. In Eq. (1) and (2), VA ratings of series inverter are computed as per Eq. (3).

$$
\begin{aligned}
& \mathrm{I}_{\mathrm{s}}=\mathrm{I}_{\mathrm{L}} \cos \phi / \mathrm{m} \\
& \mathrm{S}_{\mathrm{se}}=\mathrm{V}_{\mathrm{se}} \mathrm{I}_{\mathrm{s}}=\mathrm{V}_{\mathrm{s}} \mathrm{I}_{\mathrm{L}} \cos \phi \sqrt{1+\mathrm{m}^{2}-2 \mathrm{~m} \cos \delta / \mathrm{m}}
\end{aligned}
$$

Eq. (5) and (4) reveals the reactive and active powers generated by series inverter, here, $\theta_{\mathrm{se}}=180^{\circ}-\tan ^{-1}(\sin \delta / 1-\cos \delta)[14]$.

$$
\begin{aligned}
& \mathrm{P}_{\mathrm{se}}=\mathrm{S}_{\mathrm{se}} \cos \theta_{\mathrm{se}} \\
& \mathrm{M}_{\mathrm{se}}=\mathrm{S}_{\mathrm{se}} \sin \theta_{\mathrm{se}}
\end{aligned}
$$

Eq. (6) shows the formulation of current via shunt inverter $I_{\text {sh }}$.

$$
\begin{aligned}
\mathrm{I}_{\mathrm{sh}} & =\sqrt{\mathrm{I}_{\mathrm{s}}^{2}+\mathrm{I}_{\mathrm{L}}^{2}-2 \mathrm{I}_{\mathrm{s}} \mathrm{I}_{\mathrm{L}} \cos (\phi-\delta)} \\
& =\mathrm{I}_{\mathrm{L}} \sqrt{1+\cos ^{2} \phi / \mathrm{m}^{2}-2 \cos \phi \cos (\phi-\delta) / \mathrm{m}}
\end{aligned}
$$

Furthermore, the shunt inverter carries out compensation of harmonics in load end as specified in Eq. (7) and (8), where $I_{s h}^{d i}$ and $I_{L}^{d i}$ points out distortion element of shunt and load, $I_{\text {sh }}^{f u}$ and $I_{L}^{f u}$ points out fundamental component of shunt and load, $\mathrm{T}_{\mathrm{L}}$ and $\mathrm{T}_{\mathrm{sh}}$ signifies THD of load and shunt inverter.

$$
\begin{aligned}
& I_{\mathrm{L}}^{\mathrm{di}}=\mathrm{I}_{\mathrm{sh}}^{\mathrm{di}} \\
& \mathrm{T}_{\mathrm{L}} \mathrm{I}_{\mathrm{L}}^{\mathrm{fu}}=\mathrm{T}_{\mathrm{sh}} \mathrm{I}_{\mathrm{sh}}^{\mathrm{fu}}
\end{aligned}
$$

Thus, r.m.s of shunt current is determined as in Eq. (9) and its VA rating is specified as in Eq. (10).

$$
\begin{aligned}
\mathrm{I}_{\mathrm{sh}} & =\mathrm{I}_{\mathrm{sh}}^{\mathrm{fu}} \sqrt{1+\mathrm{T}_{\mathrm{sh}}^{2}} \\
& =\mathrm{I}_{\mathrm{L}}^{\mathrm{fu}} \sqrt{1+\cos ^{2} \phi / \mathrm{m}^{2}-2 \cos \phi \cos (\phi-\delta) / \mathrm{m}+\mathrm{T}_{\mathrm{L}}^{2}} \\
\mathrm{~S}_{\mathrm{sh}} & =\mathrm{V}_{\mathrm{s}} \mathrm{I}_{\mathrm{sh}} \\
& =\mathrm{V}_{\mathrm{s}} \mathrm{I}_{\mathrm{L}}^{\mathrm{fu}} \sqrt{1+\cos ^{2} \phi / \mathrm{m}^{2}-2 \cos \phi \cos (\phi-\delta) / \mathrm{m}+\mathrm{T}_{\mathrm{L}}^{2}}
\end{aligned}
$$

Eq. (11), (12) and Eq. (13) illustrates the active, reactive powers and total reactive power delivered by shunt inverter. $\theta_{\mathrm{sh}}=\tan ^{-1}\{\cos (\phi-\delta)-\cos \phi / \sin (\phi-\delta)\}+90^{\circ}-\delta$.

$$
\begin{aligned}
& \mathrm{P}_{\mathrm{sh}}=\mathrm{S}_{\mathrm{sh}} \cos \theta_{\mathrm{sh}} \\
& \mathrm{M}_{\mathrm{sh}}=\mathrm{S}_{\mathrm{sh}} \sin \theta_{\mathrm{sh}} \\
& \mathrm{M}_{\mathrm{UPQC}}=\mathrm{M}_{\mathrm{se}}+\mathrm{M}_{\mathrm{sh}}
\end{aligned}
$$

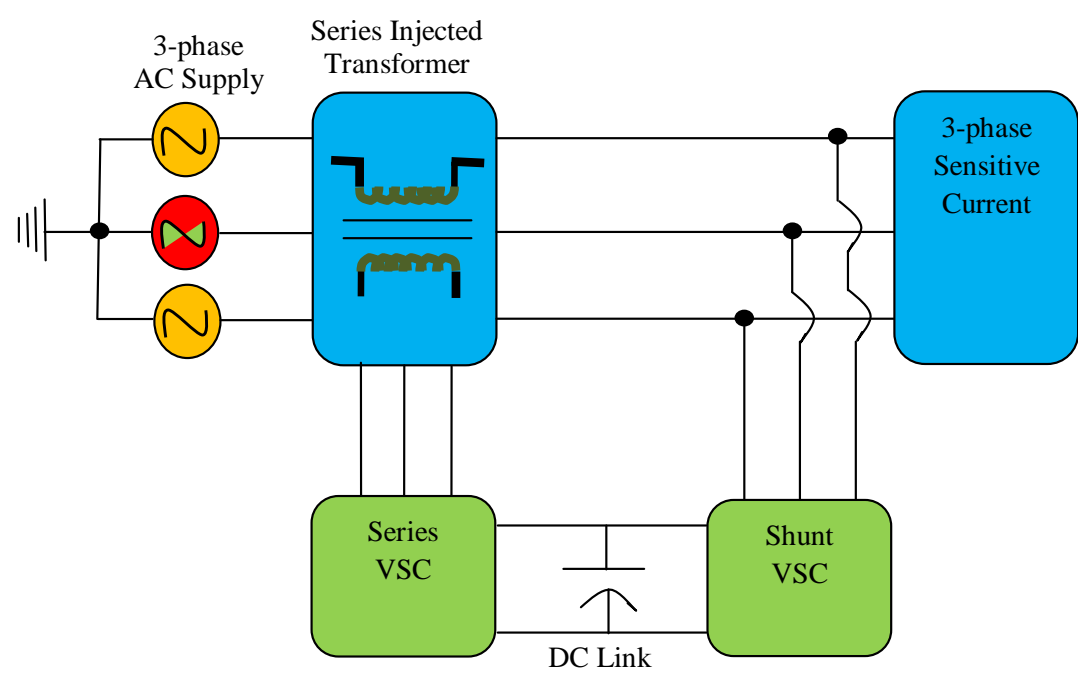

Fig. 1. Pictorial representation of $U P Q C$ 


\subsection{Objective Model}

In fact, the placement of UPQC should satisfy the objectives for enhancing PQ. Eq. (14) demonstrates the objectives of presented scheme. Eq. (17) shows Lo computation, where $\mathrm{O}_{\mathrm{k}}$ points out conductance of $\mathrm{m}^{\text {th }}$ line and voltage angles of $\mathrm{i}$ and $\mathrm{j}$ buses is signified as $\delta_{\mathrm{i}}$ and $\delta_{\mathrm{j}}$. The cost of UPQC is specified by Eq. (15), where, nUPQC points out UPQC's longevity, O points out UPQC's operating level in MVAr, $\mathrm{UPQC}_{\text {Cost }_{\text {year }}}$ points out annual cost of $\mathrm{UPQC}, \mathrm{UPQC}_{\text {Cost }}$ points out investment cost, $\mathrm{R}$ points out asset rate of return. The VSI is measures as in Eq. (16), where $\mu$ points out a constant, $\mathrm{V}^{\mathrm{b}}$ points out voltage magnitude for $b^{\text {th }}$ bus.

$$
\begin{aligned}
& \mathrm{OB}=\min \left(\mathrm{UPQC}_{\text {cost }}+\mathrm{Lo}+\mathrm{VSI}\right) \\
& \mathrm{UPQC}_{\text {Cost }}(\mathrm{US}(\$ / \mathrm{kVAr}))=0.0003 \mathrm{O}^{2}-0.2691 \mathrm{O}+188.22 \\
& \mathrm{UPQC}_{\text {Cost }}{ }_{\text {year }}=\mathrm{UPQC}_{\text {Cost }} \frac{(1-\mathrm{R})^{\mathrm{nUPQC}} \times \mathrm{R}}{(1+\mathrm{R})^{\mathrm{nUPQC}}-1} \\
& \mathrm{VSI}=\left\{\begin{array}{lc}
1 & \text { if } \quad \mathrm{V}^{\min } \leq \mathrm{V}^{\mathrm{b}} \leq \mathrm{V}^{\max } \\
\exp \left(\mu\left|1-\mathrm{V}^{\mathrm{b}}\right|\right) & \text { otherwise }
\end{array}\right\} \\
& \mathrm{Lo}=\sum_{\mathrm{m}=1}^{\mathrm{N}_{\mathrm{L}}} \mathrm{Lo}_{\mathrm{m}}=\sum_{\mathrm{m}=1}^{\mathrm{N}_{\mathrm{L}}} \mathrm{O}_{\mathrm{m}}\left\{\mathrm{V}_{\mathrm{i}}^{2}+\mathrm{V}_{\mathrm{j}}^{2}-2 \mathrm{~V}_{\mathrm{i}} \mathrm{V}_{\mathrm{j}} \cos \left(\delta_{\mathrm{i}}-\delta_{\mathrm{j}}\right)\right\}
\end{aligned}
$$

The inequality and equality constraints are briefed below.

\section{Equality Constraints}

In fact, the line powers are addressed by voltage magnitude and phase angles [15]. Eq. (18) and Eq. (19) shows the active and reactive power balances respectively.

$$
\begin{aligned}
& \mathrm{P}_{\mathrm{H}_{\mathrm{i}}}-\mathrm{P}_{\mathrm{E}_{\mathrm{i}}}-\sum_{\mathrm{m}=1}^{\mathrm{N}_{\mathrm{L}}} \mathrm{o}_{\mathrm{im}}\left\{\mathrm{V}_{\mathrm{i}}^{2}+\mathrm{V}_{\mathrm{j}}^{2}-2 \mathrm{~V}_{\mathrm{i}} \mathrm{V}_{\mathrm{j}} \cos \left(\delta_{\mathrm{i}}-\delta_{\mathrm{j}}\right)\right\}=0 \\
& \mathrm{M}_{\mathrm{H}_{\mathrm{i}}}-\mathrm{M}_{\mathrm{E}_{\mathrm{i}}}-\sum_{\mathrm{m}=1}^{\mathrm{N}_{\mathrm{L}}} \mathrm{p}_{\mathrm{im}}\left\{\mathrm{V}_{\mathrm{i}}^{2}+\mathrm{V}_{\mathrm{j}}^{2}-2 \mathrm{~V}_{\mathrm{i}} \mathrm{V}_{\mathrm{j}} \sin \left(\delta_{\mathrm{i}}-\delta_{\mathrm{j}}\right)\right\}=0
\end{aligned}
$$

In Eq. (18) and (19), $\mathrm{P}_{\mathrm{H}_{\mathrm{i}}}$ and $\mathrm{P}_{\mathrm{E}_{\mathrm{i}}}$ points out active power and active power demand at $\mathrm{i}^{\text {th }}$ bus, $\mathrm{P}_{\text {loss }}$ points out total active power loss. $\mathrm{M}_{\mathrm{H}_{\mathrm{i}}}$ and $\mathrm{M}_{\mathrm{E}_{\mathrm{i}}}$ points out reactive power and $\mathrm{m}$ reactive power demand at $i^{\text {th }}$ bus, $Q_{\text {loss }}$ indicates the reactive power loss. $o_{i-j}$ and $p_{i-j}$ points out conductance and susceptance among $i$ and $j . V_{i}$ and $V_{j}$ points out voltage magnitude of $i$ and $j$ buses.

\section{Inequality Constraints}

These constraints are classified into major groups.

Line flow limit: The constraint for power flow limit is determined as per Eq. (20), here $\mathrm{S}_{\mathrm{m}^{\max }}$ points out highest power flow value at $\mathrm{m}^{\text {th }}$ line.

$$
\mathrm{SE}_{\mathrm{m}} \leq \mathrm{SE}_{\mathrm{m}^{\max }}
$$

Bus voltage limit: It takes account of both voltage unbalance and magnitude limit nodes based on the condition specified in Eq. (21).

$$
\mathrm{V}^{\min }<\mathrm{V}<\mathrm{V}^{\max }
$$

\section{Optimal Allocation And Sizing of UPQC Via GWO-SA Algorithm}

\subsection{Solution Encoding}

For attaining the objectives, the size and positions of UPQC on "IEEE 33 bus system and the IEEE 69 bus systems" are given as solutions as shown in Fig. 2, where $\mathrm{Pt}_{\mathrm{a}}$ points out the bus line positions and $\mathrm{Si}_{z_{\mathrm{N}}}$ points out UPQC size. Here, $\mathrm{a}=1,2,3 . \mathrm{N}$, in which, $\mathrm{N}=33$ and $\mathrm{N}=69$ for IEEE 33 and IEEE 69 bus systems, correspondingly. 


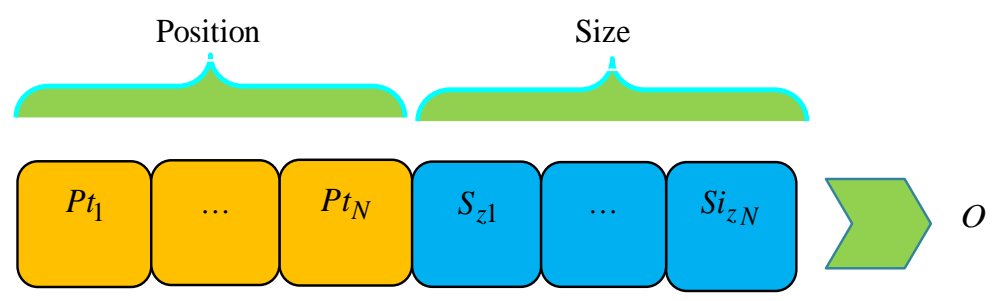

Fig. 2. Solution encoding

\subsection{GWO-SA Algorithm}

The GWO [13] portrays the hunting characteristics of grey wolves and its control hierarchy. Four kinds of wolves namely, $\alpha, \eta, \zeta, \omega$ are considered for performing the headship hierarchy. The wolves namely, $\alpha$, $\eta$ and $\zeta$ are involved in hunting process. Among them $\alpha$ takes decision on hunting model and sleeping locations, $\eta$ and $\zeta$ aids $\alpha$ in taking choices. The encircling nature of wolves are revealed as in Eq. (22) and Eq. (23), here Xand Y represent the coefficient vectors, $\mathrm{O}_{\mathrm{p}}$ and $\mathrm{O}$ indicate position vector of prey and grey wolves and tindicate the current iteration. Consequently, $\mathrm{X}$ and $\mathrm{Y}$ is computed as per Eq. (24) and Eq. (25), and $r_{1}$ and $r_{2}$ reveal the arbitrary vectors amongst [0, 1]. As per GWO-SA model, a is calculated as per Eq. (26), here $\tau$ indicates the change of fitness as shown in Eq. (27), if $t \neq 1$, or else, the value of $\tau$ is considered. In Eq. (27), $f(t-1)$ and $f(t)$ points out the previous and present iterations in that order.

$$
\begin{aligned}
& \mathrm{Z}=\left|\mathrm{Y} \cdot \mathrm{O}_{\mathrm{p}}(\mathrm{t})-\mathrm{O}(\mathrm{t})\right| \\
& \mathrm{O}_{\mathrm{p}}(\mathrm{t}+1)=\mathrm{O}_{\mathrm{p}}(\mathrm{t})-\mathrm{X} \cdot \mathrm{Z} \\
& \mathrm{X}=2 \mathrm{a} \cdot \mathrm{r}_{1}-\mathrm{a} \\
& \mathrm{Y}=2 \mathrm{r}_{2} \\
& \mathrm{a}=\tau *\left(2-1 *\left(\frac{2}{\mathrm{t}_{\max }}\right)\right) \\
& \tau=\frac{(\mathrm{f}(\mathrm{t}-1)-\mathrm{f}(\mathrm{t}))}{\mathrm{f}(\mathrm{t}-1)}
\end{aligned}
$$

The arithmetical formulation for illustrating the hunting character of wolf is exposed by Eq. (28) to Eq. (33) and the final position of wolves is revealed in Eq. (34).

$$
\begin{aligned}
& \mathrm{Z}_{\alpha}=\left|\mathrm{Y}_{1}-\mathrm{O}_{\alpha}-\mathrm{O}\right| \\
& \mathrm{Z}_{\eta}=\left|\mathrm{Y}_{2}-\mathrm{O}_{\eta}-\mathrm{O}\right| \\
& \mathrm{Z}_{\zeta}=\left|\mathrm{Y}_{3}-\mathrm{O}_{\zeta}-\mathrm{O}\right| \\
& \mathrm{O}_{1}=\mathrm{O}_{\alpha}-\mathrm{X}_{1} \cdot\left(\mathrm{Z}_{\alpha}\right) \\
& \mathrm{O}_{2}=\mathrm{O}_{\eta}-\mathrm{X}_{2} \cdot\left(\mathrm{Z}_{\eta}\right) \\
& O_{3}=O_{\zeta}-X_{3} \cdot\left(\mathrm{Z}_{\zeta}\right) \\
& \mathrm{O}(\mathrm{t}+1)=\frac{\mathrm{O}_{1}+\mathrm{O}_{2}+\mathrm{O}_{3}}{3}
\end{aligned}
$$

\section{Results and Discussions}

\subsection{Simulation Procedure}

The presented approach was executed in MATLAB and the outcomes were observed. This work considered 2 diverse bus systems such as "IEEE 69 bus system and IEEE 33 bus system". In addition, 3 experiments were done based on UPQC allocation (i) 1 location (ii) 2 locations (iii) 3 locations. Furthermore, the analysis of presented model was carried out by altering the loading conditions to " $0 \%$, $50 \%, 100 \%, 150 \%, 200 \%$, and $250 \% "$ correspondingly. Here, the supremacy of presented model was proved over the existing models such as SLnO [16], GWO [21], DA [18] and PSO [19]. 


\subsection{Performance Analysis: IEEE 33 Bus System}

This division portrays the analysis of the presented work over the existing works for "IEEE 33 bus system" for varied number of locations such as 1,2, and 3. The performance of the implemented work when the number of location=1 is shown in Table II. On observing the Table, the GWO-SA model has achieved a higher performance than existing schemes with respect to reduced fitness value. Table II reveals the analysis of presented work over the existing works when the number of location=2. On examining Table I, the GWO-SA model at $0 \%$ loading condition is $0.21 \%, 0.59 \%, 0.77 \%$ and $0.26 \%$ better than SLnO, GWO, DA and PSO, respectively. Likewise, for all loading conditions, the presented work has attained optimal outcomes than the existing ones.

Table 1: Performance of presented work over existing works for varied Loading Conditions (location count $=1$ )

\begin{tabular}{llllll}
\hline Loading (\%) & SLnO & GWO & DA & PSO & GWO-SA \\
\hline $\mathbf{0}$ & 515.15 & 517.12 & 518.07 & 515.4 & 514.08 \\
$\mathbf{5 0}$ & 556.84 & 561.09 & 561.28 & 561.19 & 553.8 \\
$\mathbf{1 0 0}$ & 599.91 & 599.91 & 599.91 & 599.91 & 592.91 \\
$\mathbf{1 5 0}$ & 642.25 & 644.29 & 642.58 & 642.46 & 641.22 \\
$\mathbf{2 0 0}$ & 690.79 & 690.9 & 694.03 & 691.02 & 688.7 \\
$\mathbf{2 5 0}$ & 740.57 & 742.06 & 740.85 & 740.81 & 739.43 \\
\hline
\end{tabular}

Table 2: Performance of presented work over existing works for varied Loading Conditions (location count = 2)

\begin{tabular}{llllll}
\hline Loading (\%) & SLnO & GWO & DA & PSO & GWO-SA \\
\hline $\mathbf{0}$ & 412.36 & 420.27 & 420.27 & 420.85 & 410.9 \\
$\mathbf{5 0}$ & 458.13 & 456.73 & 457.22 & 457.22 & 459.07 \\
$\mathbf{1 0 0}$ & 495.2 & 493.03 & 495.19 & 495.78 & 493.69 \\
$\mathbf{1 5 0}$ & 543.16 & 541.1 & 541.74 & 541.3 & 533.19 \\
$\mathbf{2 0 0}$ & 589.88 & 587.25 & 589.33 & 588.94 & 585.07 \\
$\mathbf{2 5 0}$ & 638.06 & 636.73 & 647.16 & 638.06 & 634.96 \\
\hline
\end{tabular}

Table 3: Performance of presented work over existing works for varied Loading Conditions (location count $=3$ )

\begin{tabular}{llllll}
\hline Loading (\%) & SLnO & GWO & DA & PSO & GWO-SA \\
\hline $\mathbf{0}$ & 378.1 & 379.68 & 387.59 & 378.17 & 377.06 \\
$\mathbf{5 0}$ & 422.47 & 424.16 & 430.56 & 422.88 & 423.02 \\
$\mathbf{1 0 0}$ & 460.17 & 460.39 & 472.61 & 459.91 & 455.06 \\
$\mathbf{1 5 0}$ & 506.88 & 508.27 & 514.98 & 514.54 & 510.25 \\
$\mathbf{2 0 0}$ & 555.97 & 554.82 & 562.81 & 554.68 & 553.32 \\
$\mathbf{2 5 0}$ & 603.71 & 605.33 & 612.77 & 606.04 & 604.2 \\
\hline
\end{tabular}

\subsection{Performance Analysis: IEEE 69 Bus System}

The analyses of presented work over existing works for "IEEE 69 bus system" are described in this subdivision. The analysis was made by varying the loading conditions for varied location counts (1, 2 and 3). Table IV demonstrates the analysis when number of location is one, Table V shows the outcomes when location count is 2 and Table VI demonstrates the analysis when number of location is three. On examining the outcomes, the presented model has satisfied the objective function in an optimal way when evaluated over the existing works.

Table 4: Performance of presented work over existing works for varied Loading Conditions (location count $=1$ )

\begin{tabular}{llllll}
\hline Loading (\%) & SLnO & GWO & DA & PSO & GWO-SA \\
\hline $\mathbf{0}$ & 543.21 & 543.21 & 537.99 & 543.21 & 536.64 \\
$\mathbf{5 0}$ & 555.86 & 555.86 & 555.86 & 549.37 & 549.35 \\
$\mathbf{1 0 0}$ & 569.88 & 563.42 & 569.88 & 570.68 & 563.42 \\
$\mathbf{1 5 0}$ & 585.31 & 580.07 & 585.31 & 580.07 & 580.07 \\
$\mathbf{2 0 0}$ & 605.71 & 604.95 & 605.35 & 604.95 & 598.63 \\
$\mathbf{2 5 0}$ & 623.4 & 623.4 & 618.15 & 623.4 & 617.11 \\
\hline
\end{tabular}


Table 5: Performance of presented work over existing works for varied Loading Conditions (location count $=21$ )

\begin{tabular}{llllll}
\hline Loading (\%) & SLnO & GWO & DA & PSO & GWO-SA \\
$\mathbf{0}$ & 446.07 & 433.2 & 443.55 & 433.39 & 432.14 \\
$\mathbf{5 0}$ & 446.01 & 445.8 & 457.37 & 455.8 & 453.1 \\
$\mathbf{1 0 0}$ & 460.99 & 473.05 & 473.05 & 467.66 & 459.75 \\
$\mathbf{1 5 0}$ & 484.71 & 475.12 & 488.34 & 474.89 & 474.46 \\
$\mathbf{2 0 0}$ & 491.65 & 491.94 & 491.87 & 493.81 & 491.78 \\
$\mathbf{2 5 0}$ & 513.18 & 513.03 & 521.19 & 524.05 & 513.81 \\
\hline
\end{tabular}

Table 6: Performance of presented work over existing works for varied Loading Conditions (location count $=3$ )

\begin{tabular}{llllll}
\hline Loading (\%) & SLnO & GWO & DA & PSO & GWO-SA \\
$\mathbf{0}$ & 402.25 & 400.03 & 400.33 & 400.42 & 395.65 \\
$\mathbf{5 0}$ & 412.89 & 412.69 & 414.42 & 412.94 & 412.79 \\
$\mathbf{1 0 0}$ & 429.27 & 426.93 & 426.79 & 424.22 & 426.71 \\
$\mathbf{1 5 0}$ & 444.67 & 442.32 & 442.39 & 441.61 & 441.19 \\
$\mathbf{2 0 0}$ & 458.7 & 458.73 & 460.98 & 458.64 & 459.13 \\
$\mathbf{2 5 0}$ & 482.47 & 480.06 & 480.81 & 477.75 & 476.13 \\
\hline
\end{tabular}

\section{Conclusion}

This work has presented a new PQ enhancement model depending on a GWO-SA approach. For enhancing the PQ, it was essential for determining the optimal position and sizing of UPQC. Here, GWOSA was exploited with the objective of minimizing cost, power loss, and stability as well. Finally, evaluation was carried out to establish the enhancement of the adopted model. On examining the outcomes, the implemented work at $0 \%$ loading condition was $0.21 \%, 0.59 \%, 0.77 \%$ and $0.26 \%$ better than SLnO, GWO, DA and PSO, respectively. Likewise, for all loading conditions, the presented work has attained optimal outcomes than the existing ones.

\section{References}

[1] S. Lakshmi and S. Ganguly, "Modelling and allocation of open-UPQC-integrated PV generation system to improve the energy efficiency and power quality of radial distribution networks," IET Renewable Power Generation, vol. 12, no. 5, pp. 605-613, 492018.

[2] Jian HanXing LiYao SunShoudao Huang, "Optimal operation of UPQC under VA capacity constraints based on hierarchical optimization", International Journal of Electrical Power \& Energy Systems, vol. 122, November 2020

[3] Shubh LakshmiSanjib Ganguly, "Multi-objective planning for the allocation of PV-BESS integrated open UPQC for peak load shaving of radial distribution networks", Journal of Energy Storage, vol. 22, pp. 208-218, April 2019.

[4] B. Vijay Kumara, N.V. Srikanth, "A hybrid approach for optimal location and capacity of UPFC to improve the dynamic stability of the power system", Indian Department of Electrical Engineering, 21 September 2016.

[5] MohamadAli AminiAlireza Jalilian, "Modelling and improvement of open-UPQC performance in voltage sag compensation by contribution of shunt units", Electric Power Systems Research, vol. 187, October 2020.

[6] S. Lakshmi and S. Ganguly, "Energy loss minimization with open unified power quality conditioner placement in radial distribution networks using particle swarm optimization, 2017 th International Conference on Power Systems (ICPS)", Pune, 2017, pp. 55-60.

[7] Om PrakashMahela and Abdul GafoorShaik, " Power quality improvement in distribution network using DSTATCOM with battery energy storage system", International Journal of Electrical Power \& Energy Systems, vol. 83, pp. 229-240, December 2016.

[8] Jayanti Sarker and S.K. Goswami, " Optimal Location of Unified Power Quality Conditioner in Distribution System for Power Quality Improvement", Electrical Power and Energy Systems, vol. 83, pp. 309-324, 2016.

[9] Anup Kumar and PandaNishantPatnaik, " Management of reactive power sharing \& power quality improvement with SRF-PAC based UPQC under unbalanced source voltage condition", International Journal of Electrical Power \& Energy Systems, vol. 84, pp. 182-194, January 2017.

[10] S. K. Khadem, M. Basu and M. F. Conlon, "Intelligent Islanding and Seamless Reconnection Technique for Microgrid With UPQC," IEEE Journal of Emerging and Selected Topics in Power Electronics, vol. 3, no. 2, pp. 483-492, June 2015.

[11] J. Ye, H. B. Gooi and F. Wu, "Optimal Design and Control Implementation of UPQC Based on Variable Phase Angle Control Method," IEEE Transactions on Industrial Informatics, vol. 14, no. 7, pp. 3109-3123, July 2018.

[12] S. Devassy and B. Singh, "Control of solar photovoltaic integrated UPQC operating in polluted utility conditions," IET Power Electronics, vol. 10, no. 12, pp. 1413-1421, 1062017. 
[13] S. Sharma, S. Bhattacharjee and A. Bhattacharya, "Grey wolf optimisation for optimal sizing of battery energy storage device to minimise operation cost of microgrid," in IET Generation, Transmission \& Distribution, vol. 10, no. 3, pp. 625-637, 2182016.

[14] Ganguly S, " Impact of unified power-quality conditioner allocation on line loading, losses and voltage stability of radial distribution systems", IEEE Trans Power Deliv, vol. 29, no. 4, 2014.

[15] Biswas S, Goswami SK, Chatterjee A, "Optimal distributed generation placement in shunt capacitor compensated distribution systems considering voltage sag and harmonics distortions", IET Gener Transm Distrib, vol. 8, no. 5, pp. 783-97, 2014.

[16] Masadeh, Raja \& Mahafzah, Basel \& Sharieh, Ahmad. "Sea Lion Optimization Algorithm", International Journal of Advanced Computer Science and Applications, vol. 10, pp. 388-395, 2019.

[17] Seyedali Mirjalili a, Seyed Mohammad Mirjalili, Andrew Lewis, "Grey Wolf Optimizer", Advances in Engineering Software, vol. 69, pp.46-61, 2014.

[18] Mohammad Jafari, Mohammad Hossein Bayati Chaleshtari, "Using dragonfly algorithm for optimization of orthotropic infinite plates with a quasi-triangular cut-out", European Journal of Mechanics - A/Solids, vol. 6, pp. 1-146, November-December 2017.

[19] Junhao Zhang, Pinqi Xia, "An improved PSO algorithm for parameter identification of nonlinear dynamic hysteretic models", Journal of Sound and Vibration, vol. 389, pp. 153-167, 17 February 2017. 